\title{
DENDRITIC MALFORMATION: A CASE STUDY ON ADAPTABLE TECTONIC SYSTEMS
}

\author{
M. MARCU \\ Assistant Professor, University of Cincinnati DAAP SAID.
}

\begin{abstract}
Departing from an understanding that our society's most acute architectural dilemma is its indefinite urban augmentation in an otherwise limited Natural context, the Dendritic Malformation research proposes to develop the complex relationships between form, space, structure, materiality and the senses, as a proposition for future modes of inhabiting and constructing the built environment. Our cities are the major conduit for global consumption of energy, air and water. The buildings we live in are the main pollutants throughout their entire life span: fabrication of building components, construction, occupation and demolition. While there is a large body of research dedicated to building green and sustainable, little attention is paid to the potential of building components as adaptive, transformative structures, which are responsive to their environment in that they adapt in shape and function to the immediate context. This involves reciprocity within the various components of a building, allowing for one element to incrementally and fluidly mutate to become another, similarly to how nature produces malformations during its natural selection process. Structure, for example, could serve multiple functions by incorporating various programmatic necessities, and through a formal and functional cross pollination of uses and performances could fluidly propagate to engage the interior (building envelope) and exterior (landscape) of the built environment. Within this context, Dendritic Malformation challenges the preconceived notion that architectural structure needs to be discontinuous, monotonous, rigid, protected behind thermal barriers and separated from its surroundings. Dendritic mutations are malleable solutions of responsive systems with a variegated ordered inspired by the self-organizing processes of nature.

Keywords: Adaptive architecture, design agency, tectonic crisis.
\end{abstract}

\section{INTRODUCTION}

In his recent book, 'Digital Culture in Architecture', Antoine Picon emphasizes the distance between the new digital avant-garde and the political and social aspects of design, and their relation to the environmental challenge. He identifies the particular moment of our time as a zoomable space in which 'form is suspended between the infinitely small and the infinitely large'. He further links the incertitude of architectural agency to the crisis of tectonics. If architecture can be understood as an analogue for human memory, inscriptions such as time are registered through its literal structure. Until a couple of decades ago, the dialogue between the parts of architecture was something that had metalinguistic connotations. Architecture was never language, but the dialogue between the different parts had something to do with the spirit of language [1].

Today, however, the problem with the digital relations is that they are not about to speak [1]. And if they would, we didn't know exactly what they would say to each other. Would they speak of national identity? According to Patrik Schumacher, that is 'another ghost that needs to be exorcized from our discipline'. In his opinion, the world's society is proliferating a multitude of new subcultures and life-styles within the complex world division of labor which architecture needs to become sensitive to. In this way, new urban identities will emerge 'from within the current white noise sameness urbanism' [2]. He is arguing, in other words, for architecture's contribution to a set of collective values.

The crisis of tectonics, however, becomes even more difficult to decipher as we become increasingly unsure of how and with whom will we build our future. Will robotization really happen? 
Without a clear answer to this question we are left with only one approach-what Descartes calls a provisional moral code- to reconstruct our tectonics.

The provisional method proposed here bridges between two parallel streams of thought, polarized by Archigram \& Archizoom at one end of the spectrum and M.C. Escher at the other, to provide for a strategic reinvention of the digital primitive hut.

\section{BACKGROUND}

In my previous research titled 'Dendritic Diagramming' I have developed, a light weight truss system composed of what I called performative dendrite members which vary function to structural needs such as span, insertion points and circulation (Fig. 1). The aggregation of the various performative dendrites arose from a close study of bubble packing. Each member was enclosed inside a tetrahedron cell with the axis of the dendritic arms subdividing the cell into sub cells. This is based on the study of Plateau borders along the edges of polyhedral cells, which always meet in fours at a vertex with an angle of about 109.5 [3]. The arrangement emerges from the requirements for mechanical stability of the cell walls. These geometrical rules govern the structures of all soap films and attest to an underlying regularity in the architecture of foams. Therefore they describe one of the most efficient systems of aggregation.

Unlike traditional truss members, the performative dendrites have the resiliency of form and tectonics to provide for an open-ended system that is inherently generative. Similar to how neuronal dendrites, due to their division adaptability can facilitate the dendritic arborization [ramification], the tectonic dendritic truss can proliferate and evolve endlessly. The dendrite network provides for a structural truss system that is free of staircases, dead ends and unused square footage, facilitating a free flowing of spaces and seamless transition of programmatic requirements.

Dendritic Malformation proposes a morphological mutation of elements, with components that drastically deform until they lose their previously legible categorization and shift to become part of an entirely different taxonomy. This anticipates a tighter connection between building components and their environment that gradually form inhabitable spaces, which in turn seamlessly recede to become landscape and blend within the urban context. The disruption of the artificial habitat, therefore, becomes congenial and unnoticeable ecologically and physically.

A close study of the working methodology used by Archigram and Archizoom starts to demonstrate hybrid copy paste techniques, which lead to divisions and a fluid confluence of form and space. M.C. Escher's drawings, on the other hand, lay out a carefully calculated methodology on how to morph one image into a tessellated pattern and then slowly alter that pattern eventually to make another. The understanding of these techniques has a direct impact on the development of a provisional method, a pseudo-code responding to the crisis of tectonics. This provisional working

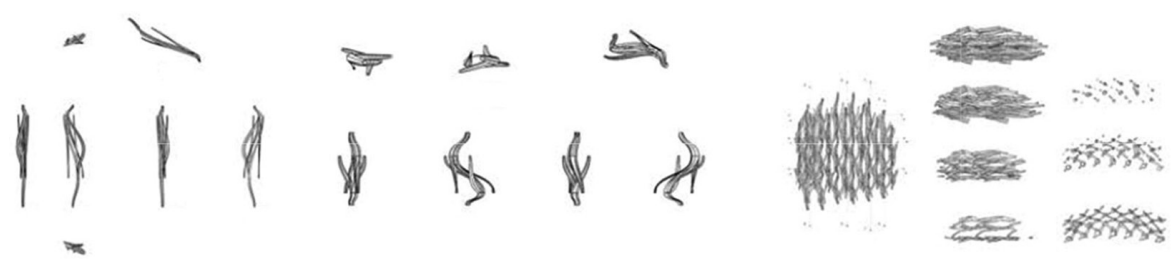

Figure 1: Performative Dendrites. 
methodology will mitigate between the incertitude regarding time, history and memory, and by reinventing their relation it will reassess design's agency whiting the digital culture.

\section{PROPOSITION}

Using Manhattan as a prototypical modern metropolis [4], this paper targets the very core of tectonics by engaging in the on-going redefinition of an otherwise obsolete architectural typology, the skyscraper [5]. A product of the industrialized age, the skyscraper represented, as its very name suggests, tangible utopia. Today, however, utopian speculation is dubious and regarded as rather suspect and definitely naive. The traditional skyscraper has surpassed the mainstream and like any totalitarian system has collapsed in terms of social relevance, has lost credibility and has been boring the public, and critical, eye for the past decades. The 'loss' of a unidimensional assumption, however, implies that we have to move on to 'the playful' and "opportunistic" browsing across multiple latent utopias that circulate as irritations between the co-evolving subsystems of society' [2].

This research proposes to understand the vertical scape as a self-generating, autopietic entity [according to Humberto Maturana and Francisco Varela definition of the term, 'the self-maintaining chemistry of living cells'], in which systems and typologies are in a continuous flux [6]. Instead of rejecting the monster [used here to define a hybrid condition; monster often defines as being part animal and part human, which diverges from the normal behavior, shape or condition; similarly to how the skyscraper is part land, part sky, part vertical, part horizontal] created, we need to evaluate it in terms of its negative, such as unidimensionality, and positive, such as extremism, heuristics [2]. In fact we may find our source of inspiration and potential resolution in the very surreal culture of congestion itself, New York. The epitome of super imposed artificial order anticipating unforeseen social structures and human interactions; New York offers a multiplicity of tentacular opportunistic synapses between unpredicted amounts of strata.

\section{FORM SELECTS FUNCTION}

Functioning in the realm of the avant-garde-as opposed of the mainstream, the formal investigation proposed intends to produce mutations, understood as opportunities, rather than solutions. The code of novelty is employed as the prerequisite while the criteria of utility and beauty is seen as secondary, fitness testing and reassuring measure.

The suspension of premature demands: function, program, site is only temporary. The methodology involves the form to program heuristics, translated as form selects function instead of function selects form [2]. While oscillating between the ludic and the investigative, the research aims at the elaboration of novel form-function relations. Function, will be here therefore understood as "capacity" or "affordance" that opens itself up to an evolutionary formation of new purposes rather than fulfilling a fully predetermined purpose [2]. The methodology includes post-rationalization and programmatic adaptability.

Instead of yet another high-rise along the High Line, this research addresses the cohesive landscape found within the interstitial space currently present. It is important to reiterate that these ideas precede the recent digital avant-garde and are in fact a century behind our present developments. In 1914 Sant' Elia was already rendering in his "Futurist Manifesto" various arrangements of planes, public spaces, stairwells and inhabitable pockets of space, while proclaiming that 'roofs and underground spaces must be used' and advocating for plastic dynamism [7]. Rem Koolhaas was promoting cross programing of space in the 1970's through the advocation of running tracks, for example, through skyscrapers [4]. For this purpose the High Line is used as a prototypical example of connections that need to be reiterated vertically, defining this way a pseudo-vertical environment. 


\section{THE PROVISIONAL METHOD}

\subsection{Learning from Archigram}

Plastic dynamism was also Archigram's agenda during the 1960's. Issues such as performance and programmatic resilience are visible in all of their drawings. 'Archigram injected flexibility with amphetamines and envisaged adaptation on a daily, if not hourly, basis', as seen in the House for 1990 [8]. Repetition is addressed for example in 'Gasket homes 1965', which uses a series of plastic strip profiles of different patterns that can be built up into an almost infinite series of enclosures. A base unit therefore is self-referenced through a hybrid process of copying, pasting, rotating and mirroring interdependently of each other's position on paper [and in space]. This synthetic aggregate is then suspended from a mega structure, which becomes the new 'capsule' that too beginnings to multiply. In many ways, these drawings have a similar hypnotic quality to the present ornamental revival in architecture. They too provide for an absence of boundary between the subject and the object. The technique they employ is that of cutting out the everyday and pasting it in relation to sometimes-iconic tectonics, such as Bucky Fuller's domes. They appropriate a present environment that becomes the fittest backdrop for the deployment of their own structures. In this way, they establish a dialogue between the present elements of architecture and 'the representation of a hypothetical visible environment made manifest simultaneously with this two-dimensional paper proxy' [8].

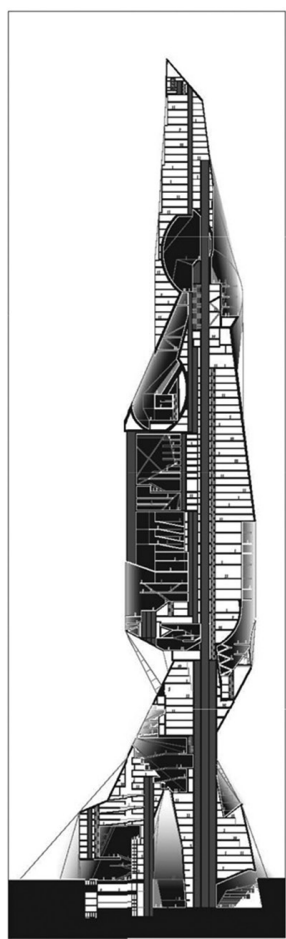

Figure 2

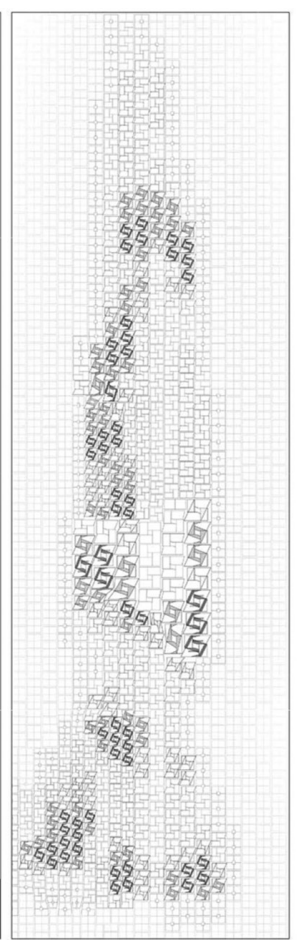

Figure 3

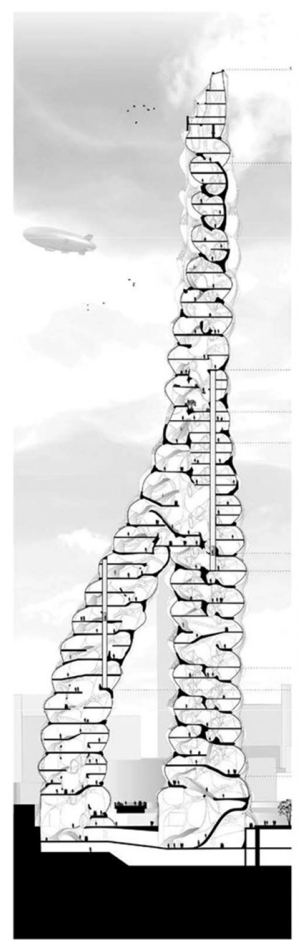

Figure 4

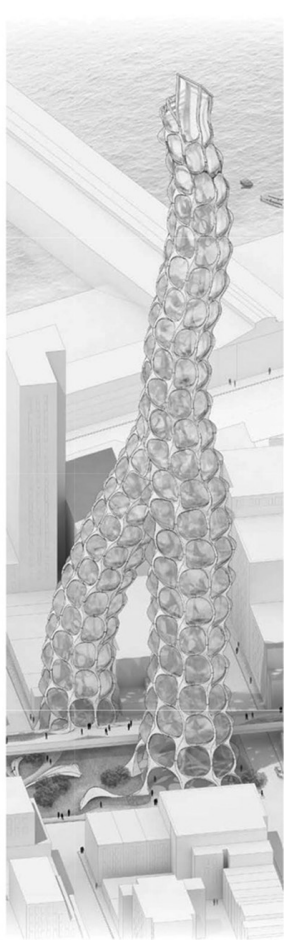

Figure 5

The Provisional Method.

Sydney Brown, former student University of Cincinnati DAAP SAID. 


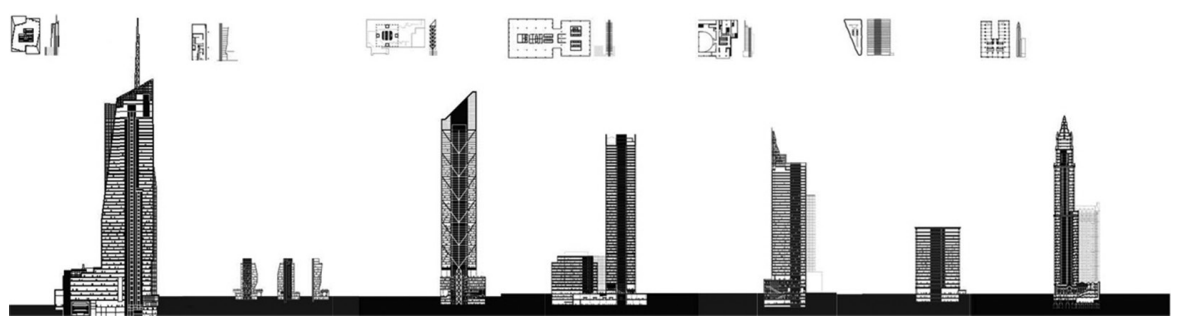

Figure 6: New York Vertical Precedents.

Erin Klein, former student University of Cincinnati DAAP SAID.
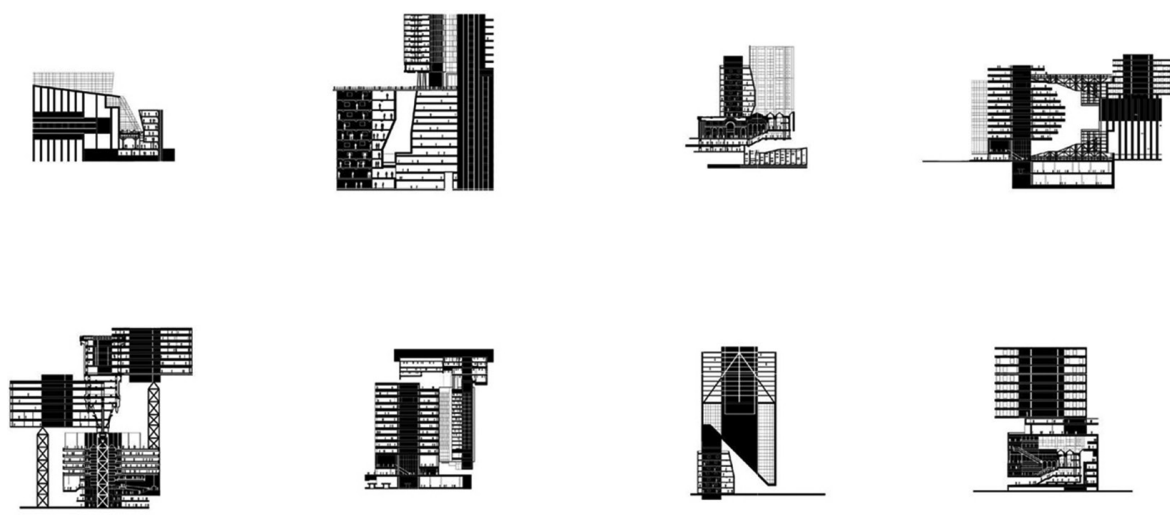

Figure 7: Pseudo Equations.

Erin Klein, former student University of Cincinnati DAAP SAID.

In the studio taught at the University of Cincinnati, this past spring, we began the provisional method with an initial documentation of 9 precedents per student, within the existing 587 skyscrapers currently found in New York City, plus others unbuilt or demolished. Each tower was traced in section, while identifying taxonomies within their organizational rational (Fig. 6).

In the spirit of the Archigram, our subsequent analysis mutated into a 'creative engagement' that includes the speculative extension [or inversion] of identified logics [2]. Implementing plagiarism as a necessary autopoietic technique, students were asked to treat each section as an open source precedent and appropriate its identity. The outcome of the first assignment lead to an assemblage of such pirated sections of itself, or partial self, at various scales that depict opportunistic interventions and anticipated novel modes of human interaction, all made possible by a pseudo code of 'paste special' operations (Fig. 7).

In the overall final composition, a new pattern of an emerging pseudo-vertical habitat began to surface. (Figs 2, 8 and 10). The presentation was paired by manifestos describing the realm rendered in the section drawings.

\subsection{Ornament: Archizoom to M.C. Escher's 'Strange Loops'}

The second step in the provisional method targets pattern extraction from the previous drawings of New York's Vertical Finest. We, hence, delve in the realm of ornament-based organization and its associated affects [9]. Pattern development targets the delineation of a descriptive order in which 


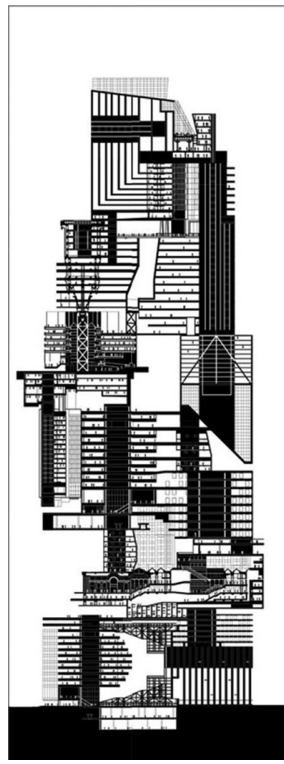

Figure 8

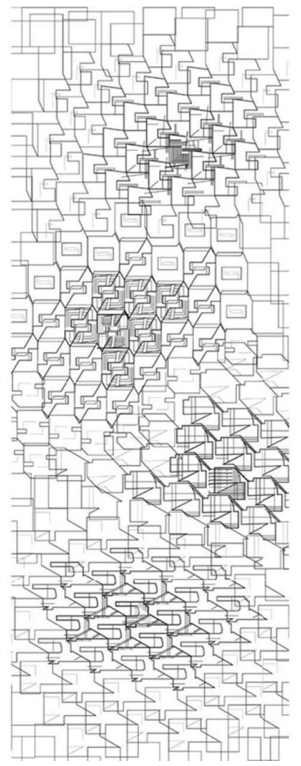

Figure 9

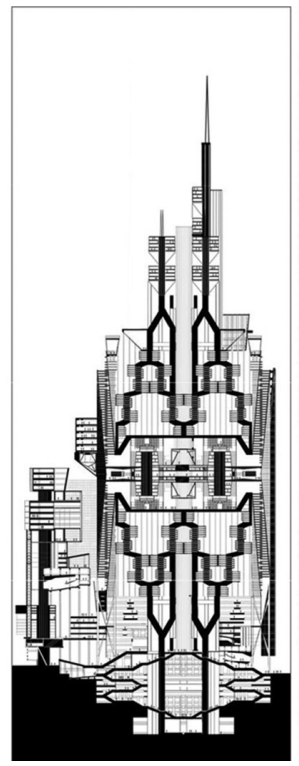

Figure 10

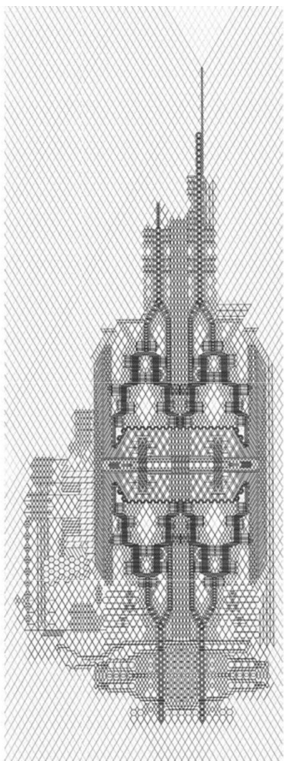

Figure 11 New York Vertical Finest and Quilts.

Erin Klein, former student University of Cincinnati DAAP SAID
Jillian Blakey, former student University of Cincinnati DAAP SAID

field conditions unfold and is understood as a scalable framework indicative of inherently rigorous and efficient possible urban arrangements. As seen in Archizoom's 'No Stop City' the ornament of the surface can counterbalance programmatic imbalance [10]. While the computer has enabled us to live outside of our bodies, the zoomable, sometimes indecipherable data network allows for continuity between the subject and the architectural object.

In music, this phenomenon is referred to as the 'strange loop', in which a pattern set by a composer, is then broken only to return whole again, as in Bach's canons. 'Implicit to the concept of Strange Loops is the concept of infinity, since what else is a loop but a way of representing an endless process in a finite way?' [11]. As seen in Escher's 'Metamorphosis', infinity plays a large role. As Hofstadter observes, copies of one single theme often fit into each other, forming visual analogues to the cannons of Bach. Through a process of tilled planes students were asked to identify a series of iconic tesserae whiting their previous sections. Studying each unit lead to a 'paste special' methodology, defining tectonic malformations of such taxonomies, the outcome becoming in itself, an abstracted strange loop of New York's Tectonic Finest (Figs 3, 9 and 11).

\subsection{Propagation}

Following, our fourth stage, included subsequent base unit delineation and aggregation that consumes one cubic foot of space. Students speculated on the development of tectonic systems resilient in their morphology, which can adjust and mutate endlessly function to context.

While reiterating the cell digitally, the issues of mass, and volume became central in characterizing a set of propagation parameters. Students were asked to aggregate the cell digitally, utilizing parametric design development environments as new cognitive opportunities (Figs 14 and 15). Reference to the previous physical investigations was stressed, however mimicking the same aggregate 


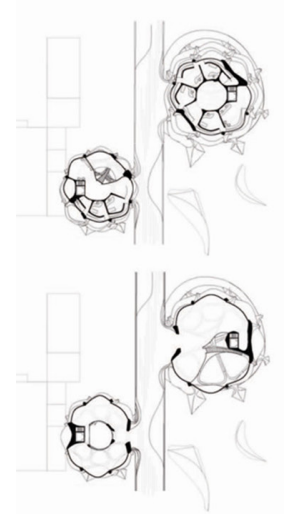

Figure 12

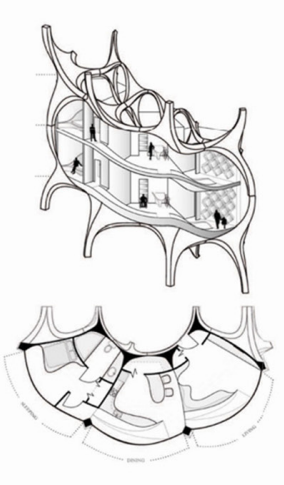

Figure 13

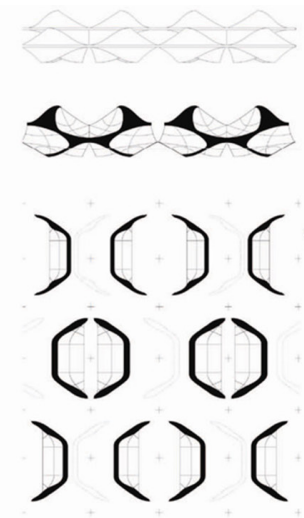

Figure 14

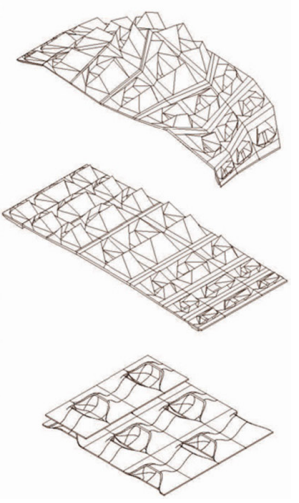

Figure 15

Typical Floor Layout, Base Unit, Aggregation.

Sydney Brown, former student University of Cincinnati DAAP SAID.
Ben Hamilton, former student University of Cincinnati DAAP SAID

proved irrelevant. The digital, therefore built on and eventually departed [as opposed to embodying] from the previous tectonic models and was studied in several 3D printed models.

Quasi-client, program and site were introduced, but left open-ended for form-selects-function strategies to crystallize. In the spirit of programmatic cross-pollination [pairing distinctly different activities], students selected programs to intersect with the qualities of the ones suggested. The client was understood as one who has suffered severe physical, mental or personal injury and one who consequently relies on the new found pseudo vertical landscape to find reconciliation. Program and utility were adapted and adopted to form as appropriate (Figs 12 and 13).

\subsection{Extremism}

This was the point of where the parametric systems previously designed were further adapted to specific site considerations and programmatic conditions initially iterated in the copy pasted master sections of New York's Vertical Finest. The extremism phase challenges the preconceived notion that architectural structure needs to be repetitive, formally identical throughout fundamentally different settings and segregated from the other architectural systems. Dendritic malformations are systems understood as morphologically adaptive, transformative structures, which are responsive to their environment in that they adapt in shape and function to the immediate habitat (Fig. 16).

Computationally speaking, correlation means that a set of parameters [proportion, position, material property] of an architectural element can be associated with the parameters of any other element of the design. For example a 12-foot office structural grid could gradually transform and adapt to a large span free plan structural system of an auditorium. The result is a gradient of structure that optimizes tectonic needs with an economy of means [material and labor]. Furthermore the same structure could mutate to form the building envelope, which can be correlated to the sun radiation intensities the façade is exposed to.

\subsection{Totalization}

This is the point of reality check when a series of technical concerns are introduced such as: structural systems, external envelope rationalization, full-scale prototyping and fabrication of a typical base unit 


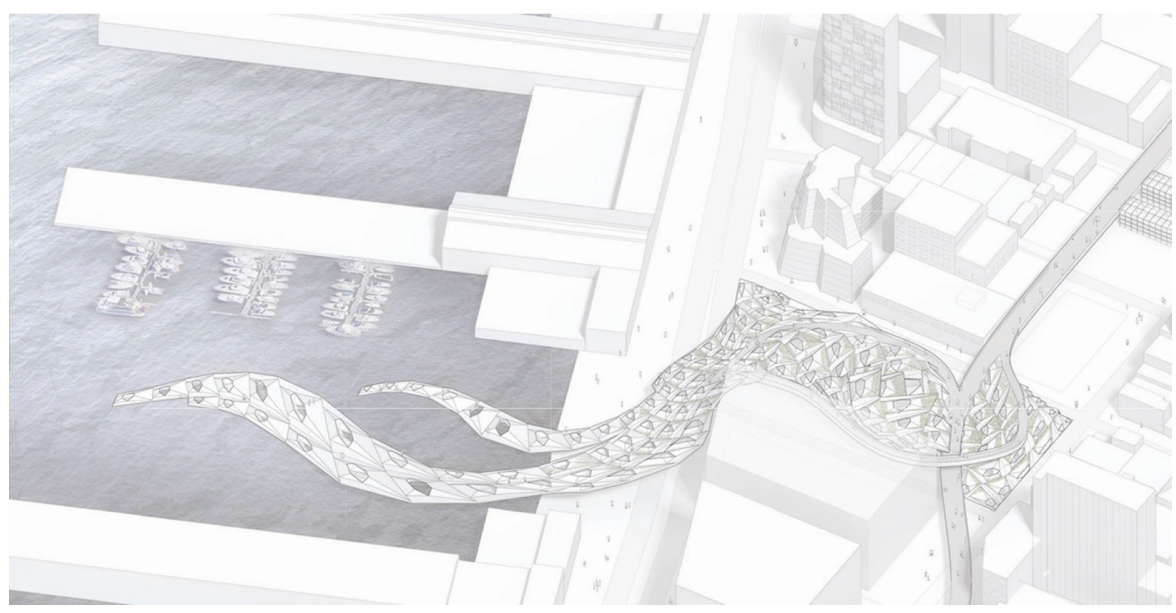

Figure 16: Extremism.

Ben Hamilton, former student University of Cincinnati DAAP SAID.

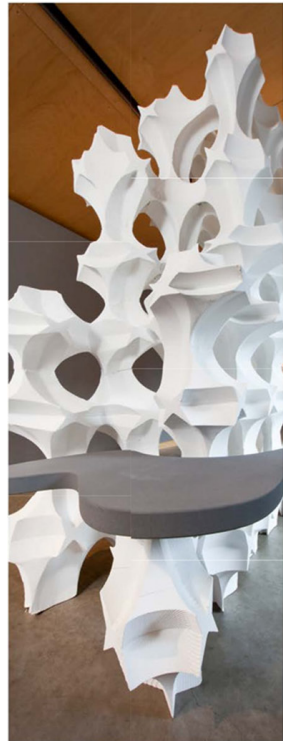

Figure 17

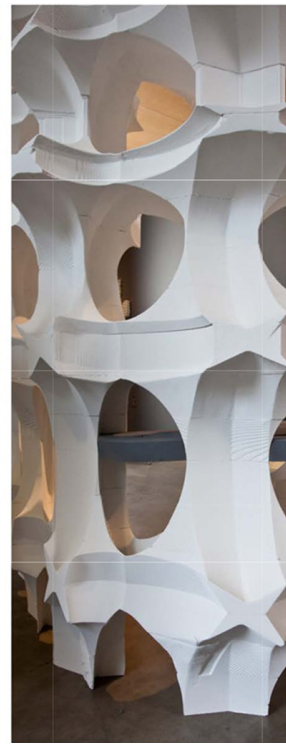

Figure 18

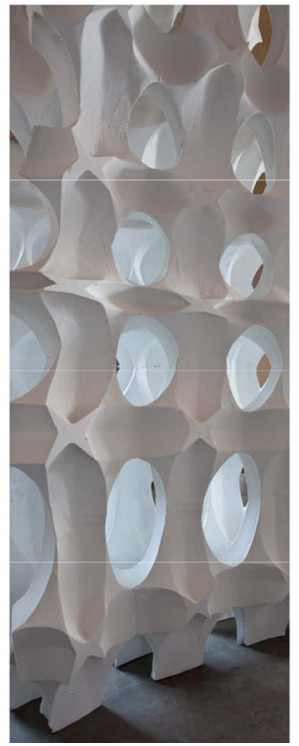

Figure 19

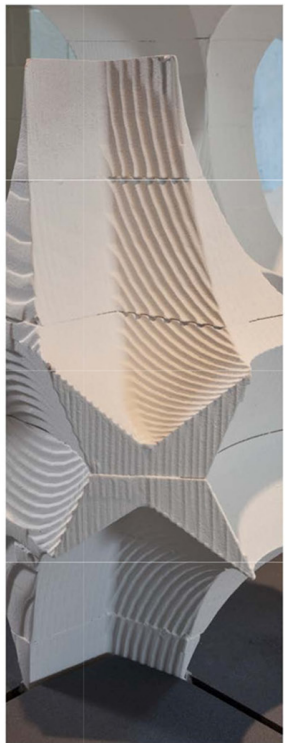

Figure 20

'Sambo_Reconfigured'.

and system aggregate. The task here is to test how these additional [necessary] subsystems are integrated innovatively to enhance [as opposed to compromise] the agency of design (Figs 4 and 5).

Digital fabrication is used to investigate through a full-scale installation, which distinguish itself from architectural models that are usually meant to be scaled up and study predictability, the potential of capturing the behavior or DNA, if you wish, of our present society in a one to one scale representation.

'Sambo_Reconfigured' (Figs 17-20) is part of a series that speculate on the cross pollination between CNC fabrication and utilitarian, landfill materials, between the old and the new, between the avant-garde and the archaic. Rather pristine synthetic tectonics are inundated by what some 
would consider disposable, throw away material insertions, seen as leftovers of human behaviors that have somehow embedded traces of contemporary mythology and mark time as consumption. The ideas explored encompass the propagation and sustainability of transiency and decay, while creating an archeological site, a repository for the release, or discharge of symbolic content.

The installation is CNC routed out of 3inch thick 'closed cell' rigid urethane foam board made specifically for applications of up $300^{\circ} \mathrm{F}$ continuous exposure, with a combination of $18 \mathrm{lbs}$. density for the base and $8 \mathrm{lbs}$. density for the upper cells.

The high-density foam used is made with certified-green eco-friendly urethane components and is recyclable, according to a recent study at Yale University conducted in 2012, in which a newly discovered Amazon fungus will digest plastic, even without oxygen. The installation is composed of two sections: one which is true to the geometry, yet follows the constraints of fabricating a undevelopable surface assembly on a three-axis router with a 1/8 step over, and the second which surrenders to the limitations of the fabrication tool while embracing the unexpected waves resulting in the structure, this time using a more accurate 1/32 stopover and a stratified slicing strategy.

The end result of the totalization phase is to provide for a digital and material workflow that connects design, fabrication, which often remains segregated from the generative process, and culture-specific topics for the purpose of mass customization [the use of flexible computer-aided manufacturing systems to produce custom output].

\section{PROJECTED SIGNIFICANCE}

The ecological, socio-economic, as well as urban crises sprung off in the wake of Modernism's demise during the 1970s. It was rooted in the commonly practiced premise that architecture is a discontinuous, monotonous, rigid, generically neutral disruption within the landscape, protected behind thermal barriers and separated from its surroundings. Today, however, architects are compelled to envision malleable solutions of responsive systems with a complex and variegated ordered inspired by the self-organizing processes of nature. This leads to reciprocity between the inside and the outside, between our artificial habitat and the natural highly consequential and synthetically adaptive fluid matrix surrounding it. It is an exciting epoch for architects, which presents itself with the obligation to chart this newfound territory.

The problem with incremental modulation, however, [here understood as sequential and slowly progressing change of a set of parameters within a field condition] is that in essence it leads to morphologically equivalent and, hence, repetitive patterns of habitation. This reads as a cellular structure in which base units gradually vary in size, without dramatically changing their configuration, structure, function or material composition. The aggregate therefore is a monotonous one. While the role of variation proved important in pushing forward an essential body of research testing or optimizing principles of mass customization

its residual effect within a culture of excess is perhaps similar to the forced historical dislocation

during Postmodernism. This on-going research seeks to mature a representational technique and a workflow for the subsequent development of tectonic mutations in architecture. Dendritic mutation [here interchangeable with malformation] is an irregular, anomalous, abnormal, or faulty formation, which has the resilience of structure, composition and form to breed a quasi-functional aggregate.

\section{CONCLUSION}

While the diagram has failed to revolutionize architecture as it proved nothing else than a Beaux Arts parti, we are left with the difficult task to re-envision what makes form happen. Will the generation of tomorrow still make form or write algorithms that generate a family of formal possibilities calibrated to a set of criteria? [12]. 
With no where to start and no answer yet known, we are left to tackle the question of a working methodology as an active, at times explosive, but most likely in flux notion. As Sanford Kwinter says, 'method is everything, data is nothing' [13]. We live in a world where the process is more real than the object but we need the objects to justify the existence of our processes.

Within the current world of multiplicity, the provisional method outlined above provides for the needed fiction to begin claiming our own freedom. While we don't know where we will go, we still need provisionary roots [14]. Within this context, design's agency addresses redefining gravity in connection but also in contrast with the lack of gravity in the digital world [14]. It's within this set of conditions that we can reassess the environmental challenge and the relation of architecture to the city.

In the most reductive sense, dendritic malformations are non-linear, anarchic, nomadic, smooth and moving in many directions, making connections to other systems while cutting across arbolic like divisions [15]. This thinking creates links between pre-existing gaps, while operating at multiple scales. Within the context of current cities and their need for novel viral and rhyzomatic interventions to address the necessity of new synthetic ecologies, dendritic diagraming, proposes subversive, yet rigorously targeted insertions at various scales. The result becomes therefore ecologically adaptive.

\section{REFERENCES}

[1] Picon, A., (2010), Digital Culture in Architecture, Birkhäuser Architecture, Germany.

[2] Schumacher, P., (2011), The Autopoiesis of Architecture. Vol. 1, John Wiley and Sons, LTD, United Kingdom.

[3] Ball, P., Bubbles, (1999), The Self Made Tapestry - Pattern Formation in Nature, pp. 16-49, Oxford Press, Cambridge.

[4] Koolhaas, R., (1994), Delirious New York, The Monacelli Press, Italy.

[5] Abalos, I., (2008), Verticalism (The Future of the Skyscraper), in: Ortega, L., Kubo, M., GSD 08 Platform, Actar, Barcelona.

[6] Maturana, H. R., Varela, F.J. (1980), Autopoiesis and Cognition: The Realization of the Living, in: Saavedra, F. C., Boston Studies in the Philosophy of Science, Vol. 42, D. Reidel Publishing Company, Holland. doi: http://dx.doi.org/10.1007/978-94-009-8947-4 9

[7] Da Costa Meyer, E., (1995), The Work of Antonio Sant'Elia: Retreat Into the Future, Yale University Press, US.

[8] Cook, P., (1999), Archigram, Princeton Architectural Press, New York.

[9] Moussavi, F., (2006), The Function of Ornament, Actar, Barcelona.

[10] Branzi, A., (1998), No-Stop City Archizoom Associati, pp. 56-59, in: Hays, K. M., Architecture theory since 1968, MIT Press, Cambridge, Massachusetts.

[11] Hofstadter, Douglas R., (1999), Introduction: A Musico- Logical Offering, Godel, Escher, Bach: An Eternal Golden Braid, pp. 2-23, Basic Books, Inc., New York. doi: http://dx.doi. org/10.2307/2273479

[12] Schodek, D. Bechthold, M. Griggs, K., (2005), Digital Design And Manufacturing, John Wiley and Sons, Inc., New Jersey.

[13] Kwinter, S., (2008), Wildness, Far From Equilibrium: Essays on Technology and Design Culture, pp. 186 - 191, Actar, Barcelona.

[14] Picon, A., (2013), Ornament: The Politics of Architecture and Subjectivity-AD Primer, John Wiley and Sons, LTD., United Kingdom.

[15] Deleuze, G., (1987), A Thousand Plateaus, University of Minnesota Press, US. doi: http:// dx.doi.org/10.5040/9781472547989 